\title{
Pain-Coping Strategies in Chronic Pain Patients: Psychometric Characteristics of the Pain-Coping Inventory (PCI)
}

\author{
Floris W. Kraaimaat and Andrea W. M. Evers
}

\begin{abstract}
This article presents a series of studies aimed at validating a comprehensive pain-coping inventory (PCI) that is applicable to various types of patients with chronic pain. Item and scale analyses were performed for patients with rheumatoid arthritis (RA), patients with chronic headache, and pain clinic outpatients. The following 6 scales were derived from a simultaneous component analysis: Pain Transformation, Distraction, Reducing Demands, Retreating, Worrying, and Resting, all of which were internally reliable. A higher order factor analysis grouped the PCI scales into active (transformation, distraction, reducing demands) and passive (retreating, worrying, resting) pain-coping dimensions. Differences in use of strategy found between RA patients and headache patients indicated that the PCI scales were sufficiently sensitive to measure differences between groups. Concurrent validity was assessed for patients with RA and patients with fibromyalgia and predictive validity was assessed for patients with recently diagnosed RA after 1 and 3 years. In both analyses the validity of the scales was supported, in particular the predictive validity of passive coping scales for future outcomes.
\end{abstract}

Key words: pain-coping strategies, active pain coping, passive pain coping, chronic pain, pain-coping inventory (PCI)

This research was supported in part by a grant from the Dutch League Against Rheumatism (Nationaal Reumafonds).

We would like to thank A. H. Bakker, M. R. Brons, J. W. J. Bijlsma, R. Geenen, C. J. A. E. Huiskes, R. E. O van Schevikhoven, and C. N. Tromp for their assistance in data collection.

Floris W. Kraaimaat and Andrea W. M. Evers, Department of Medical Psychology, University Medical Center, University of Nijmegen, Nijmegen, The Netherlands.

Correspondence concerning this article should be addressed to Floris W. Kraaimaat, University Medical Center St Radboud, Department of Medical Psychology 118, P.O. Box 9101, 6500 HB Nijmegen, The Netherlands. E-mail: f.kraaimaat@cukz.umcn.nl 
Pain is one of the most universal types of stress. Statistics show staggering figures on the number of patients for whom pain is a major problem, including those with arthritis, back pain, or headache. Estimates of the prevalence of chronic pain in the general population range from $2 \%$ to $40 \%$ (Verhaak, Kerssens, Dekker, Sorbi, \& Benzing, 1998). Patients with chronic pain pose a problem in terms of their suffering, the impact on their families, time lost from employment, medical expenses, costs associated with disability compensation, and the utilization of health care resources. It has become abundantly clear that there is no isomorphic relation between tissue damage and pain reported. Though recurrent nociception was demonstrated in the pain of patients with arthritis and migraines, there were no definite organic findings for about half of the chronic pain patients.

Cognitive and behavioral reactions to pain are significant because they may affect pain, functional capacity, and psychological functioning and may be amenable to change brought about by interventions. These reactions to pain are commonly studied under the category "pain coping" and defined as people's behavioral and cognitive attempts to manage or tolerate pain and its effects (e.g., Brown \& Nicassio, 1987; Jensen, Turner, Romano, \& Strom, 1991). Coping with pain can be classified into general active strategies for relieving, controlling, or functioning with pain and general passive strategies that include withdrawal, avoidance, and negative self-statements about pain. Furthermore, the strategies can be divided into cognitive and behavioral strategies. In addition, pain-coping actions and cognitions can be positive or negative, respectively adaptive or maladaptive, depending on their immediate or long-term consequences regarding pain, physical functioning, psychosocial functioning, or a combination of all three.

There is currently substantial literature on the relation between coping with chronic pain and physical and psychological adjustment (e.g., Jensen, Turner, Romano, \& Karoly, 1991). Studies among adult pain patients suggest that general passive coping categories (e.g., withdrawal, resting, worrying-catastrophizing) are associated with poorer outcomes, such as decreased physical functioning and increased psychological distress (e.g., Smith, Wallston, Dwyer, \& Dowdy, 1997). General active coping strategies (e.g., continuing activities despite pain, ignoring pain), hypothesized as beneficial by many authors, were not found consistently related to beneficial outcomes (Brown \& Nicassio, 1997; Smith et al., 1997), possibly due to the fact that the effects of active coping are more contex sensitive than those of passive coping (Smith et al., 1997). There are several unanswered questions about the relation between specific coping strategies and physical and psychosocial functioning (Boothby, Thorn, Stroud, \& Jensen, 1999). Although passive strategies are generally maladaptive, some are probably more maladaptive than others, whereas some active strategies could be more worthwhile than others. Moreover, for training purposes it is more advantageous to stimulate or discourage specific coping skills than, for instance, to tell patients to refrain from passive strategies (Jensen, Turner, Romano, \& Strom, 1995). Finally, regarding the severity of 
pain and pain coping, simple, linear relations cannot necessarily be expected in chronic pain patients. Pain coping may be instigated when in pain or to prevent pain. Its effects for the patient can bring about a decrease, an ability to tolerate, or an increase of pain; and short- and long-term effects can vary between strategies.

Various inventories for measuring pain-coping strategies have been developed. One assumption on which pain-coping inventories (PCIs) are based is that individuals generalize to a certain degree across situations and come up with a limited set of strategies that can be reapplied on different occasions. There is no standardized comprehensive measure with a balanced inclusion of cognitive and behavioral coping responses. In addition, there is no instrument applicable to various categories of patients with chronic pain. The commonly used self-report measures assess pain coping in subtypes of chronic pain patients, measure relatively broad categories of pain coping, or measure solely cognitive or behavioral coping responses. For example, the Coping Strategies Questionnaire (CSQ; Rosenstiel \& Keefe, 1983) was developed to assess coping strategies in patients with chronic low back pain. The CSQ assesses six cognitive and two behavioral coping strategies including Diverting Attention, Reinterpreting Pain Sensation, Coping Self-statements, Ignoring Pain Sensations, Praying or Hoping, Catastrophizing, Increasing Activity Level, and Increasing Pain Behaviors. These strategies are grouped into three scales, that is, Cognitive Coping and Suppression, Helplessness and Diverting Attention, and Praying. Although the CSQ is used in various chronic pain disorders, factor analytic studies have failed to find a reliable factor structure across patient samples (Lawson, Reesor, Keefe, \& Turner, 1990; Spinhoven, ter Kuile, Linssen, \& Gazendam, 1989; Tuttle, Shutty, \& DeGood, 1991). The Vanderbilt Pain Management Inventory (VPMI; Brown \& Nicassio, 1987) was developed for patients with arthritis. It consists of 19 items, and a factor analysis of data from a sample of patients with rheumatoid arthritis identified two strategies: Active Coping (efforts to function in spite of pain, distraction) and Passive Coping (depending on others, wishful thinking, restricting functioning). The Pain Cognition List (PCL; Vlaeyen, Geurts, Kole-Snijders, Schuerman, Groenman, \& van Eek, 1990) consists of 50 items that assess the following five cognitive pain-coping strategies in patients with chronic back pain: Pain Impact, Catastrophizing, Outcome Efficacy, Acquiescence, and Reliance on Health Care. The Chronic Pain-Coping Inventory (CPCI) was developed as a complementary measure for behavioral strategies targeted for change in a multidisciplinary treatment to address the shortcomings of the CSQ, VMPI, and other common PCIs (Jensen et al., 1995). The CPCI consists of 58 items reflecting 8 coping strategies that tend to be encouraged (Exercise and Muscle Stretching, Task Persistence, Relaxation, Coping Self-statements), as well as strategies that are generally discouraged (Guarding, Resting, Asking for Assistance, Use of Medication). To address the rather general nature of the VMPI, a more multidimensional instrument with 49 items and 11 subscales, the Vanderbilt Multidimensional Pain Management Inventory (VMPCI) was developed by Smith 
et al. (1997) for use in patients with rheumatoid arthritis (RA). Their results indicate that the multidimensional VMPCI provided a more differentiated picture of the relation between coping and prospective measures of adjustment than the two-dimensional VPMI in RA patients.

Although a variety of inventories have been developed to assess coping reactions to different types of chronic pain, it is difficult to generalize or extrapolate research results from one study to another and from one pain condition to another. The CSQ, VPMI, VMPCI, and PCL have been developed in specific subtypes of chronic pain patients, for example, (low-) back pain patients (CSQ, PCL) or arthritis patients (VPMI, VMPCI). There is evidence to suggest that strategies identified in specific subtypes of chronic pain patients are inapplicable to other types, as indicated by factor analytic studies of the CSQ (Lawson et al., 1990; Spinhoven et al., 1989; Tuttle et al., 1991). Moreover, there is no inventory that assesses different cognitive and behavioral strategies in a balanced way.

This article presents a series of studies aimed at validating a comprehensive inventory, the PCI (Kraaimaat, Bakker, \& Evers, 1997; Kraaimaat \& Schevikhoven, 1988; Schevikhoven \& Kraaimaat, 1987), which was designed to meet the following criteria: (a) assesses specific cognitive and behavioral pain-coping strategies, (b) is applicable to various types of chronic pain patients, and (c) is easy to administer and is time efficient.

\section{METHOD}

\section{Participants}

Participants were recruited from various studies (Evers, Kraaimaat, Geenen, \& Bijlsma, 1998; Evers et al., 2001; 1990; Kraaimaat, Bakker, \& Evers, 1997; Kraaimaat, Brons, Geenen, \& Bijlsma, 1995; Kraaimaat \& Schevikhoven, 1988; Schevikhoven \& Kraaimaat, 1987). They included patients with rheumatoid arthritis, patients with chronic headaches, pain clinic patients, and patients with fibromyalgia.

Patients with rheumatoid arthritis (RA). Data were collected from two samples of 275 and 352 RA outpatients from the Rheumatology departments at three hospitals in the vicinity of Utrecht, the Netherlands. The RA diagnosis was assessed for all patients by a rheumatologist according to the 1987 ACR criteria (Arnett et al., 1988). Minimum age was set at 18 years.

The sample of 275 RA patients was used to study reliability of the inventory (Study 1) and to compare the pain-coping strategies with other chronic pain patients (Study 3). In this sample, mean age was 58.4 years $(S D=13.8)$ and mean duration of illness was 14.8 years $(S D=12.5)$. Most were female patients $(64 \%)$ and 
married (70\%). Eighty-three percent had a primary or secondary educational level (on average 7 and 12 years of education, respectively). In addition, a subsample of 78 patients was used to study test-retest reliability (Study 2). In this subsample, $61 \%$ of the patients were women. Mean age was 58.9 years $(S D=11.6)$ and mean duration of illness was 15.9 years $(S D=9.2)$. Most patients had a primary or secondary education $(83 \%)$.

The sample of 352 RA patients was used to study convergent validity (Study 4). In this sample, mean age was 56.2 years $(S D=12.0)$ and mean duration of disease was 7.0 years $(S D=7.5)$. Most patients were women $(67 \%)$, married $(78 \%)$, and had a primary or secondary educational level $(85 \%)$. To study predictive validity of the PCI (Study 5), a subsample of 78 recently diagnosed patients were followed during a 3-year period. This sample was predominantly women (69\%), married or living with a partner $(76 \%)$, and had primary or secondary $(89 \%)$ education. The mean age when entering this study was 57.0 years $(S D=14.0)$.

The demographic data of all samples concur with what is known about representative populations with RA (Evers, Taal, et al., 1998; Huiskes et al., 1990).

Patients with chronic headaches. Questionnaires were sent to a random sample of 650 members of the Dutch Society of Migraine Patients. Four hundred forty-four patients completed and returned the questionnaires. Data from 410 patients were useful for analysis. Patient mean age was 44.7 years $(S D=11.7)$, mean duration of illness 26.6 years $(S D=14.5)$, and the majority $(80 \%)$ were women. An analysis of headache symptoms revealed the presence of the following types of headache in the sample: migraine, tension headache, and the combination of both (Schevikhoven \& Kraaimaat, 1987). Generally, the sample consisted of patients with moderate to severe headaches. Because research has shown that various headache symptoms are often combined, attempts were not made to differentiate between types of headache (see also Bakal, Kaganov, \& Demjen, 1983). Sixty-nine percent of the patients had a primary or secondary level of education. The sample had more women, was slightly older, and exhibited a longer duration of disease than samples obtained through general practitioners (e.g., Post, 1980).

Pain clinic outpatients. Data were collected from 104 consecutive patients who had visited the outpatient pain clinic at the Groningen University Hospital. Patients were asked to complete a number of questionnaires as part of the intake procedure. The patient mean age was 41.4 years $(S D=11.2)$, their mean duration of illness $8.4 \mathrm{yrs}(S D=8.2)$, and $48 \%$ were women. Seventy-nine percent of the patients had a primary or secondary education. Patients had a variety of pain complaints. Back pain was present in $26 \%$ of the patients, abdominal pain in $13 \%$, pain in the extremities in $10 \%$, headache in $10 \%$, no specific location $9 \%$, and miscellaneous pain sites in $33 \%$ (e.g., neck, stomach, and jaw pain). Age, duration of dis- 
ease, and types of pain are representative for patients who seek treatment at outpatient pain clinics (e.g., Kleinke, 1992).

Patients with fibromyalgia. Questionnaires were sent to a random sample of 450 members of the Dutch Society of Fibromyalgia. Three hundred ninety-seven patients completed and returned the questionnaires. Data on 324 patients were useful for analysis. Patient mean age was 48.5 years $(S D=9.0)$ and mean duration of illness was 7.9 years $(S D=4.9)$. Most patients were women (94 $\%)$ and married $(81 \%)$. Ninety-four percent of the patients had a primary or secondary education. The demographic data and duration of disease are representative of fibromyalgia patients who seek treatment (e.g., Burckhardt, Mannerkorpi, Hedenberg, \& Bjelle, 1994)

\section{MEASURES}

Demographic variables were assessed with a general checklist. In addition, educational level was measured using seven categories that can be classified as primary, secondary, and tertiary educational levels, representing on average 7, 12, and 17 years of education, respectively.

\section{Pain}

The Pain scale of the "Impact of Rheumatic diseases on General health and Lifestyle" (IRGL; Evers, Taal, et al., 1998; Huiskes, Kraaimaat, \& Bijlsma, 1990) was used for RA patients and fibromyalgia patients. The Pain scale contains six items related to the severity of pain over the past month. The questionnaire was originally developed for arthritis patients. For the use in fibromyalgia patients, the pain scale was slightly adjusted by eliminating arthritis-specific words (swollen joints, morning stiffness, arthritis). The range of the scale was 6-25 and the alphas ranged between .86 and .92 (Evers, Taal, et al., 1998; Huiskes et al., 1990). Pain in headache patients was assessed with the Severity scale of the Headache Questionnaire (Kraaimaat \& Zwart, 1984). The range of this scale is 3-12 and its alpha .82. An index of pain intensity in pain clinic outpatients was obtained from their pain diaries by using the patients' ratings on a 10-point scale of their highest level of pain for 5 consecutive days.

\section{Functional Disability}

Functional disability in RA and fibromyalgia patients was assessed with a standardized nonweighted composite score of the IRGL Mobility and Self-Care scales. The Mobility and Self-Care scales assess the functional capacities of the lower and 
upper extremities over the past month, respectively. The standardized alphas for the IRGL Mobility and Self-Care scale range between .87 and .92 (Evers, Taal, et al., 1998; Huiskes et al., 1990). To study predictive validity in patients with recently diagnosed RA, functional disability was assessed with a standardized, nonweighted composite score of one clinical measure (mean of three grip strength assessments on both hands with a Martin vigorimeter) and the Mobility and Self-Care scales of the IRGL (see Evers, Kraaimaat, et al., 1998). Higher scores indicate higher levels of functional disability in all samples.

\section{Anxiety and Depressive Mood}

The IRGL Anxiety and Depressive Mood scales were completed by the RA and fibromyalgia patients. The Anxiety scale is a shortened version of the Dutch State Anxiety Scale (10 STAI items; Van der Ploeg, Defares, \& Spielberger, 1980), which assesses anxiety level over the past month. The Depressed Mood scale (6 items) is derived from Zwart and Spooren's questionnaire (1982) and assesses various depressed mood states over the previous 2 weeks. The standardized alphas for the IRGL Anxiety and Depressed Mood scales range between .87 and .92 (Evers, Taal, et al., 1998; Huiskes et al., 1990).

\section{Stress Coping}

Strategies for coping with stress in everyday life were assessed in RA and fibromyalgia patients with the Utrecht Coping List (UCL; Schreurs, Willige, Brosschot, Tellegen, \& Graus, 1993). Active stress coping was assessed in RA patients with the Problem-Focusing scale ( 7 items measuring cognitive and behavioral efforts to use goal-oriented problem-solving strategies) and passive stress coping with the Avoidance scale ( 8 items measuring cognitive and behavioral attempts to avoid, escape, and acquiesce when facing everyday problems). In a sample of the Dutch population Sanderman and Ormel (1992) obtained alphas for these scales of .79 and .74 , respectively.

Neuroticism was measured by a Dutch version of the Eysenck Personality Questionnaire (H. J. Eysenck \& S. B. Eysenck, 1992; Wilde, 1970). Cronbach's $\alpha$ s previously reported range between .85 and .89 (Evers et al., 2001).

Illness cognitions in RA and fibromyalgia patients were measured with two scales from the Illness Cognition Questionnaire (ICQ; Evers et al., 2001): helplessness (focusing on the adverse aspects of the disease and generalizing them to daily functioning) and acceptance (recognizing the need to adapt to a chronic disease while perceiving the ability to tolerate and manage its aversive consequences). Cronbach's $\alpha$ s for these scales ranged between .88 and .91 (Evers et al., 2001). 


\section{RESULTS}

\section{Study 1: Item Generation and Selection, Factor Structure, Internal Consistency, and Second Order Factorial Structure}

The first stage in scale development was to generate a list of items that represented a wide range of coping activities relevant to coping with pain (see Schevikhoven \& Kraaimaat, 1987). New items were generated from the literature on experimental and clinical pain and items were adapted from existing inventories (Geden, Beck, Hauge, \& Pohlman, 1984; Lipton \& Marbach, 1983; Pilowsky \& Spence, 1976; Rosenstiel \& Keefe, 1983; Scott \& Clum, 1984; Tan, 1982; Tesler, Wegner, Savedra, Gibbons, \& Ward, 1981). In addition, to increase ecological validity, items were generated from the transcribed behavioral interviews of 27 patients with various chronic pain syndromes, who were referred to a pain clinic. In the first stage 114 items were compiled that covered a variety of coping strategies. The authors shortened this list to 66 items by eliminating redundancies. To facilitate this, we solicited feedback from researchers and professionals working with chronic pain patients. In the second and quantitative stage of this study, 275 patients with RA, 441 headache patients, and 104 pain clinic outpatients were asked to rate the 66 items on a 4-point Likert scale ranging from 1 (hardly ever) to 4 (very often) in terms of the frequency with which strategies were suffering pain.

Simultaneous component analysis. Descriptive statistics were calculated for each of the 66 items. Items with a skewness, a kurtosis, or both, $>1$ or $<-1$ in the samples were removed from the initial item pool of 66 items. These 16 items, related to social support and nonallopathic treatments, were used too infrequently to be relevant to further analysis.

Subsequently, simultaneous component analysis (SCA; Kiers \& Ten Berge, 1989; Millsap \& Meredith, 1988), oblique rotation, was used to investigate the optimum dimensional structure of the remaining 50 items for the three different samples. This method can be used to analyze a set of variables observed in two or more populations. The purpose of this method is to find simultaneous components for different populations that can be easily interpreted. In SCA components weights are found that define components that optimally account for the amounts of variance in the different populations simultaneously. The same component weights are used to define components in all populations. First, the component weights (with varimax rotation of weights, followed by oblique procedure) were determined for all three samples. Then, the loadings of the items were calculated for different samples and the factorial structure was determined.

Items with a factor loading $<.40$ on all factors in at least one of the samples were removed. This was the case in 11 of the 50 items. SCA was repeated on the 39 remaining items and resulted in a seven-factor structure, explaining $47 \%$ of the 
variance in the RA patients, $46 \%$ of the variance in the headache patients, and $48 \%$ in the pain clinic outpatients. The following labels were assigned to the factors: $1=$ Pain Transformation; 2 = Distraction; 3 = Reducing Demands; 4 = Retreating; 5 = Worrying; 6 = Resting; and 7 = Comforting Cognitions.

Coefficients for internal consistency (alpha coefficients) were calculated for the seven factors across samples. One factor, Comforting Cognitions, was removed from further analysis because of insufficient internal consistency (alpha for RA patients $=.57$, headache patients $=.42$, and pain clinic outpatients $=.60$ ). Item content, factor labels, factor loadings, and alpha coefficients for the remaining six factors are presented in Table 1 . The alphas obtained are sufficiently high for research purposes and comparing groups (Nunnally \& Bernstein, 1994). After this procedure the final scale was composed, consisting of 33 items.

Relation to patient characteristics. The association between PCI scales and patient characteristics was examined with Pearson product-moment correlations. Gender was not significantly related to the scale scores in the three samples. Regarding age, significant but low correlations were found for Retreating and Resting in RA patients ( $r=.17$ and $r=.16$, respectively), and for Distraction, Reducing Demands, and Worrying in headache patients $(r=-.11, r=-.11$, and $r=$ -.13 , respectively). Illness duration was significantly related in RA patients to Transformation, Retreating, and Resting ( $r=.23, r=.15$ and $r=.14$, respectively) and in headache patients with Transformation, Distraction, Reducing demands, and Worrying ( $r=.11, r=.11, r=.11$, and $r=.12$, respectively). However, the explained variance was very low (range 1 to $4 \%$ ), insofar as significant coefficients were revealed between age and illness duration with the coping scales. Pain level was not related to pain-coping strategies in the three patient groups. An exception to this were the significant coefficients between pain severity and Worrying ( $r=$ $.10)$ in headache patients and between pain severity and Resting $(r=.24)$ in pain clinic outpatients. No significant correlations were found for age and illness duration in the group of pain clinic outpatients.

Without taking very low correlations into consideration $(r<.24)$, one may conclude that PCI scales are relatively stable regarding gender, age, and illness duration in patients with chronic pain.

Second-order factor structure. Pearson product-moment correlations were calculated between the PCI scales for all pain patients $(N=789)$. In addition, a second-order factor analysis (Principal Component Analysis, oblique rotation, eigenvalue $>1$ ) was performed on the scale scores. As can be seen in Table 2, an oblique two-factor model, explaining $57 \%$ of the total variance, adequately represented the observed correlation matrix.

The first factor was composed of the scales of Pain Transformation, Distraction, and Reducing Demands. These scales reflect both cognitive and behavioral efforts 
TABLE 1

Item Content, Factor Labels, Factor Loadings, and Internal Consistencies $(\alpha)$ in Three Types of Chronic Pain Patients

\begin{tabular}{|c|c|c|c|c|}
\hline No. Item content & & $R A$ & $H$ & $P C$ \\
\hline \multicolumn{5}{|l|}{ Factor 1: Pain Transformation } \\
\hline 15. I pretend the pain is not present. & & .81 & .75 & .76 \\
\hline 16. I pretend pain does not concern my body. & & .79 & .80 & .72 \\
\hline 18. I imagine pain to be less violent than it really is. & & .79 & .71 & .76 \\
\hline 30. I think of other people's difficulties. & & .61 & .60 & .68 \\
\hline & $\alpha$ & .75 & .67 & .70 \\
\hline \multicolumn{5}{|l|}{ Factor 2: Distraction } \\
\hline 9. I take a bath or shower. & & .58 & .58 & .55 \\
\hline 19. I think of pleasant things of events. & & .73 & .55 & .73 \\
\hline 20. I distract myself by undertaking a physical activity. & & .63 & .66 & .58 \\
\hline 21. I distract myself by reading, listening to music, etc. & & .63 & .68 & .64 \\
\hline 22. I do something I find pleasant. & & .77 & .75 & .78 \\
\hline & $\alpha$ & .69 & .64 & .67 \\
\hline \multicolumn{5}{|l|}{ Factor 3: Reducing Demands } \\
\hline 2. I continue activities with less effort. & & .82 & .84 & .70 \\
\hline 3. I continue activities with a slower pace. & & .84 & .88 & .83 \\
\hline 4. I continue activities less precisely. & & .77 & .76 & .73 \\
\hline & $\alpha$ & .73 & .77 & .62 \\
\hline \multicolumn{5}{|l|}{ Factor 4: Retreating } \\
\hline 10. Make sure that I don't get upset. & & .54 & .61 & .61 \\
\hline 11. I retreat into a restful environment. & & .73 & .79 & .72 \\
\hline 12. I avoid bothering sounds. & & .68 & .80 & .66 \\
\hline 13. Avoid light. & & .51 & .73 & .62 \\
\hline 14. I am careful of what I eat or drink. & & .47 & .44 & .47 \\
\hline 32. Separate myself. & & .67 & .67 & .65 \\
\hline 33. When outdoors I try to return home soon. & & .59 & .58 & .62 \\
\hline & $\alpha$ & .69 & .78 & .71 \\
\hline \multicolumn{5}{|l|}{ Factor 5: Worrying } \\
\hline 17. Focus on the pain all the time. & & .50 & .47 & .55 \\
\hline 23. Self-administration of other physical stimuli. & & .56 & .40 & .50 \\
\hline 24. Think of things that remain undone because of pain. & & .71 & .66 & .54 \\
\hline 25. I start worrying. & & .68 & .63 & .75 \\
\hline 26. I wonder about the cause of the pain. & & .60 & .63 & .60 \\
\hline 27. I think that the pain will get worse. & & .72 & .55 & .66 \\
\hline 28. Think about moments free of pain. & & .52 & .57 & .54 \\
\hline 29. I think I will go mad with pain. & & .56 & .59 & .67 \\
\hline 31. Others do not understand what it is to be in pain. & & .64 & .57 & .64 \\
\hline & $\alpha$ & .79 & .75 & .77 \\
\hline \multicolumn{5}{|l|}{ Factor 6 : Resting } \\
\hline 1. I stop my activities. & & .65 & .69 & .71 \\
\hline 5. I confine myself to simple activities. & & .66 & .45 & .53 \\
\hline 6. I do not exert myself physically. & & .67 & .70 & .66 \\
\hline 7. I rest sitting or lying down. & & .78 & .80 & .77 \\
\hline \multirow[t]{2}{*}{ 8. I assume a comfortable bodily posture. } & & .69 & .68 & .71 \\
\hline & $\alpha$ & .72 & .68 & .70 \\
\hline
\end{tabular}

Note. $\mathrm{RA}=$ rheumatoid arthritis $; \mathrm{H}=$ headache $\mathrm{PC}=$ outpatients pain clinic. 
TABLE 2

Correlation Matrix and Factor Loadings of Second Order Factor Analysis

\begin{tabular}{lcccccrr}
\hline Scale & 1 & 2 & 3 & 4 & 5 & Factor 1 & Factor 2 \\
\hline 1. Pain transformation & - & & & & & .82 & .02 \\
2. Distraction & $.49^{*}$ & - & & & & .81 & -.18 \\
3. Reducing demands & $.21^{*}$ & $.19^{*}$ & - & & & .52 & .06 \\
4. Retreating & $-.17^{*}$ & $-.35^{*}$ & -.08 & - & & -.34 & .80 \\
5. Worrying & $.15^{*}$ & -.00 & .08 & $.40^{*}$ & - & .21 & .75 \\
6. Resting & -.03 & .00 & -.02 & $.40^{*}$ & $.24 *$ & -.01 & .69 \\
\hline
\end{tabular}

$* p<.001$ (two-tailed).

by patients to distract themselves from the pain or to function in spite of pain. The second factor consisted of the Retreating, Resting, and Worrying scales, reflecting patients' behavioral tendencies to restrict functioning and negative cognitions about the pain. The two-factor solution is consistent with Brown and Nicassio's (1987) distinction in Active and Passive pain coping, and supports their notion that active and passive categories of coping are rather independent.

\section{Study 2: Temporal Stability}

The purpose of Study 2 was to investigate the temporal stability of the PCI scales. Stability was investigated with a 6-month test-retest interval in a subsample of 78 patients with RA. Relatively high test-retest stability for the pain-coping scales was expected when comparing individuals with the same kind of stressor (i.e., pain) at two distinct points in time.

Results. Test-retest reliability was estimated with Pearson's product-moment correlations. The following coefficients were obtained: Pain Transformation $r=.67$, Distraction $r=.73$, Reducing Demands $r=.43$, Retreating $r=.71$, Worrying $r=.82$, and Resting $r=.71$. The results indicate relatively high stability for the PCI scales over a 6-month period. Paired $t$ tests did not reveal significant differences between first and second assessments of the PCI scales.

\section{Study 3: Sensitivity to Differences Between Pain Groups}

There are some indications in the literature that pain-coping use differs among patients with different types of chronic pain (Keefe et al., 1991; Martin, Milech, \& Nathan, 1993; Philips \& Jahanshahi, 1985), suggesting that patients with chronic RA demonstrate more active and less passive coping behaviors than headache patients. This information raises the question whether the PCI is sensitive enough to measure differences in the use of specific strategies between both diagnostic pain 
groups. Data from the following groups of participants was used in this study: 275 RA patients, 441 headache patients, and 104 pain clinic outpatients. Because pain clinic outpatients present various pain complaints, no specific hypothesis was formulated for this group.

Results. Mean scale scores were calculated by dividing the raw scale score by the number of its items in order to enable comparison of strategy use within groups (Table 3).

Because significant differences between the three groups in age $(F=121.3, p<$ $.001)$, gender $(F=21.8, p<.001)$, and illness duration $(F=111.1, p<.001)$ were found, differences between groups were assessed by means of ANCOVA with age, gender, and illness duration as covariates. Post hoc Student-Newman-Keuls tests $(p<.05)$ were applied to the adjusted means to examine differences between groups. Item means (and standard deviations) on the PCI scales, $F$ values for differences between groups and results of the post hoc test between groups are presented in Table 3.

Results show differences in the use of pain-coping strategies, depending on the type of pain patients, with the exception of Resting. RA patients and pain clinic outpatients scored significantly higher on the active pain-coping scales of Pain Transformation, and Distraction, and significantly lower on the passive-coping scales of Retreating and Worrying than headache patients. RA patients and pain clinic outpatients did not differ significantly regarding these scales. In addition, RA patients used Reducing demands more often than the pain clinic outpatients and headache patients.

As shown in Table 3, the three most frequent strategies RA patients and pain clinic outpatients used were Resting and the two active strategies of Pain Transfor-

TABLE 3

Pain Coping Strategies in Three Types of Chronic Pain Patients

\begin{tabular}{|c|c|c|c|c|c|c|c|c|}
\hline \multirow[b]{2}{*}{ Scales } & \multicolumn{2}{|c|}{$R A$} & \multicolumn{2}{|c|}{$H$} & \multicolumn{2}{|c|}{$P C$} & \multirow{2}{*}{$\begin{array}{c}F \\
\text { Groups }\end{array}$} & \multirow{2}{*}{$\begin{array}{c}\text { Post hoc } \\
\text { tests (SNK) }\end{array}$} \\
\hline & $M$ & $S D$ & $M$ & $S D$ & $M$ & $S D$ & & \\
\hline \multicolumn{9}{|l|}{ Active Pain Coping } \\
\hline Transformation & 2.3 & 0.7 & 1.8 & 0.6 & 2.1 & 0.6 & $42.57 *$ & $\mathrm{RA}, \mathrm{PC}>\mathrm{H}$ \\
\hline Distraction & 2.3 & 0.6 & 1.7 & 0.5 & 2.2 & 0.6 & $106.18^{*}$ & $\mathrm{RA}, \mathrm{PC}>\mathrm{H}$ \\
\hline Reducing demands & 2.1 & 0.7 & 2.0 & 0.7 & 1.8 & 0.6 & $7.91 *$ & $\mathrm{RA}>\mathrm{H}, \mathrm{PC}$ \\
\hline \multicolumn{9}{|l|}{ Passive Pain Coping } \\
\hline Retreating & 1.7 & 0.5 & 2.9 & 0.6 & 1.6 & 0.6 & $298.84 *$ & $\mathrm{H}>\mathrm{RA}, \mathrm{PC}$ \\
\hline Worrying & 1.8 & 0.5 & 2.2 & 0.6 & 1.6 & 0.6 & $12.83^{*}$ & $\mathrm{H}>\mathrm{RA}, \mathrm{PC}$ \\
\hline Resting & 2.4 & 0.6 & 2.5 & 0.6 & 2.4 & 0.6 & 1.02 & \\
\hline
\end{tabular}

Note. $\mathrm{RA}=$ rheumatoid arthritis $\mathrm{H}=$ headache; $\mathrm{PC}=$ outpatients pain clinic. $* p<.001$. 
mation and Distraction, whereas headache patients most frequently used the strategies of Retreating, Worrying, and Resting.

\section{Study 4: Convergent Validity}

The convergent validity of the six PCI scales was examined separately among 352 patients with RA and 324 patients with fibromyalgia by computing Pearson product-moment correlations between PCI scales and measures on neuroticism, anxiety and depressive mood, functional disability, illness cognitions, and stress coping.

Relations were predicted on the basis of several sets of assumptions. The first set concerns the relation to passive pain coping and measures that reflect negative affectivity. Accordingly, positive correlations of Retreating, Worrying and Resting with neuroticism, anxiety, and depressive mood were predicted.

Second, moderate positive relations were expected between functional disability and the passive pain-coping scales of Retreating, Worrying, and Resting. Regarding the severity of pain and pain coping, simple, linear relations cannot necessarily be expected in chronic pain patients. However, pain-coping strategies are likely to be more applied in patients with higher levels of pain, predicting small to moderate relations between the scales and pain.

Thirdly, moderate positive correlations were anticipated between the illness cognition Helplessness and the passive pain-coping scales of Retreating, Worrying and Resting. And moderate positive correlations were assumed between the illness cognition Acceptance and the active pain-coping scales of Pain Transformation, Distraction and Reducing Demands.

Though associated with different sources of stress, it was assumed that stress coping and pain coping represent similar domains and are related. The fourth set of assumptions concerns the following relations: low to moderate positive correlations of the active pain-coping scales of Pain Transformation, Distraction and Reducing demands with the active stress coping scale of Problem focusing; low to moderate positive correlations of the passive pain-coping scales Retreating and Resting with the passive stress coping scale of Avoidance.

Correlations not predicted were exploratively computed. Predicted (bold) and explored (plain) relations are presented in Tables $4 \mathrm{a}$ and $4 \mathrm{~b}$ for both groups of patients, respectively.

Results. In Tables $4 \mathrm{a}$ and $4 \mathrm{~b}$, the Pearson product-moment correlations are presented between PCI scales and convergent measures for patients with RA and patients with FM, respectively.

For neuroticism, anxiety, and depressive mood, and the relation to the specific passive pain-coping scales, all predictions in RA patients and most predictions in fibromyalgia patients were significant and in the expected direction. That means that relatively high levels of neuroticism, anxiety, and depressive mood were re- 
TABLE 4a

Convergent Validity of the Pain Coping Inventory Scales in Patients with RA

\begin{tabular}{|c|c|c|c|c|c|c|}
\hline & $\begin{array}{c}\text { Pain } \\
\text { Transformation }\end{array}$ & Distraction & $\begin{array}{l}\text { Reducing } \\
\text { Demands }\end{array}$ & Retreating & Worrying & Resting \\
\hline Neuroticism & .23 & .00 & .10 & $.35 * *$ & $.50 * *$ & $.27 * *$ \\
\hline Anxiety & .08 & $-.18 * *$ & $.12 *$ & $.33 * *$ & $.56 * *$ & $.28 * *$ \\
\hline Depressive mood & .10 & $-.11^{*}$ & .09 & $.32 * *$ & $.46 * *$ & $.22 *$ \\
\hline Functional disability & $.14 *$ & .05 & .09 & $.27 * *$ & $.34 * *$ & $.45 * *$ \\
\hline Pain & $.13 *$ & .00 & $.14 *$ & $.12 *$ & $.33 * *$ & $.25 * *$ \\
\hline Helplessness & .09 & -.06 & $.12 *$ & $.34 * *$ & $.54 * *$ & $.44 * *$ \\
\hline Acceptance & .04 & $.20 *$ & -.01 & -.08 & $-.40 * *$ & $-.15^{*}$ \\
\hline Problem focusing & $.25 * *$ & $.23 * *$ & $.13 *$ & $.13 *$ & -.10 & .00 \\
\hline Avoidance & $.23 * *$ & $.18^{* *}$ & .07 & $.35 *$ & $.22 * *$ & $.26 * *$ \\
\hline
\end{tabular}

Note. Predicted (bold) and explored (plain) relations are presented for both groups of patients. $* p<.05, * * p<.01$ (two-tailed).

TABLE 4b

Convergent Validity of the Pain Coping Inventory Scales in Patients With Fibromyalgia

\begin{tabular}{|c|c|c|c|c|c|c|}
\hline & $\begin{array}{c}\text { Pain } \\
\text { Transformation }\end{array}$ & Distraction & $\begin{array}{l}\text { Reducing } \\
\text { Demands }\end{array}$ & Retreating & Worrying & Resting \\
\hline Neuroticism & $.11 *$ & $-.16^{*}$ & .01 & $.19 * *$ & $.52 * *$ & .03 \\
\hline Anxiety & .08 & $-.31 * *$ & -.05 & $.20 * *$ & $.49 * *$ & .00 \\
\hline Depressive mood & .06 & $-.16 * *$ & -.01 & $.22 * *$ & $.44 * *$ & .09 \\
\hline Functional disability & $.12 *$ & $.14^{*}$ & -.05 & $.29 * *$ & $.25 * *$ & $.41 * *$ \\
\hline Pain & $.20 * *$ & .06 & .01 & $.17 * *$ & $.28 * *$ & $.17 * *$ \\
\hline Helplessness & .06 & -.05 & -.06 & $.39 * *$ & $.54 * *$ & $.28 * *$ \\
\hline Acceptance & -.02 & $.17 * *$ & .04 & $-.22 * *$ & $-.53 * *$ & -.04 \\
\hline Problem focusing & $.23 * *$ & $.27 * *$ & .01 & $.11 *$ & $-.16^{* *}$ & -.05 \\
\hline Avoidance & .00 & .10 & $.24 * *$ & $.16^{* *}$ & $.16 * *$ & $.20 * *$ \\
\hline
\end{tabular}

Note. Predicted (bold) and explored (plain) relations are presented for both groups of patients. $* p<.05, * * p<.01$ (two-tailed)

lated to more frequent use of Retreating and Worrying in both groups and to more frequent use of Resting in RA patients.

Low levels of functional disability were associated in both groups of patients with high levels of Retreating, Resting, and Worrying. In addition, small relations were found between most of the scales and the level of pain.

High levels of Helplessness and passive stress coping (Avoidance) were related in both groups of patients to more frequent use of Retreating, Worrying, and Resting. High levels of Acceptance were related to Distraction in both groups. Ac- 
tive stress coping (Problem focusing) was found to be significantly related to Pain Transformation and Distraction in both groups of patients.

Generally speaking, negative affectivity, functional disability and pain, helplessness, and passive stress coping were found to be consistently associated with specific passive pain-coping strategies in both groups of patients. Relations between active pain-coping scales and active stress coping and Acceptance were less consistent and significant in about $50 \%$ of the predictions.

Similar results were obtained when testing these predictions more strictly, using one-tailed tests and the Bonferroni approach to control for experimental error in the analyses.

\section{Study 5: Predictive Validity}

There is evidence to suggest that the absence of passive-avoidance-oriented pain-coping strategies is related to a better functional status over time, whereas the adaptive function of active strategies has been less frequently demonstrated. For example, Brown and Nicassio (1987) demonstrated that a greater use of passive pain coping predicted less physical activity 6 months later in chronic RA patients. Keefe, Brown, Wallston, and Caldwell (1989) found that greater use of the catastrophizing strategy predicted exacerbated functional disability 6 months later in chronic RA patients, whereas more frequent use of active pain-coping strategies (patients' attempts to distract themselves from the pain and function in spite of pain) predicted high physical activity at the 6-month follow-up. The purpose of this study was to assess the degree to which passive pain-coping strategies are predictive of a deterioration in functional status after 1 and 3 years in patients with recently diagnosed RA. In addition, the extent to which active pain-coping strategies is predictive of an improvement in functional status after 1 and 3 years was explored.

The sample consisted of 78 successive outpatients with recently diagnosed RA, who completed the PCI at the time of diagnosis and measures of functional disability at the time of diagnosis and after 1 and 3 years. These patients are part of a clinical prospective trial (see also Everdingen, Jacobs, Siewertsz van Reesema, \& Bijlsma, 2002; Evers, Kraaimaat et al., 1998)

Results. Table 5 presents the Pearson product-moment correlations between the pain-coping scales at the time of diagnosis and the functional status residual change scores after 1 and 3 years.

Relatively high levels of Retreating, Worrying, and Resting were associated with high functional disability after 1 year. Of the passive pain-coping scales, only Resting was found to be predictive of high functional disability 3 years later. In conclusion, our findings are consistent with those in the literature on passive pain coping. In terms of active pain-coping strategies, more frequent use of Distraction was associated with a relatively low functional disability at 1 and at 3 years. Pain 
TABLE 5

Correlations Between Pain Coping Strategies at the Time of Diagnosis and Change in Functional Disability After 1 and 3 Years in Patients with RA

\begin{tabular}{lll}
\hline & 1 year & 3 year \\
\hline Active pain coping & & \\
Transformation & -.05 & -.07 \\
Distraction & $-.26^{*}$ & $-.26^{*}$ \\
Reducing demands & -.01 & -.05 \\
Passive pain coping & & \\
Retreating & $.26^{*}$ & .16 \\
Worrying & $.34^{* *}$ & .20 \\
Resting & $.36^{* *}$ & $.24^{*}$ \\
\hline
\end{tabular}

Note. Residual change scores were used as change scores. Positive scores indicate that pain coping strategies are related to an increase in functional disability.

$* p<.05, * * p<.01$.

Transformation and Reducing demands were found to be unrelated to change in functional disability at 1 and 3 years after diagnosis.

\section{GENERAL DISCUSSION}

The purpose of this series of studies was to assess the psychometric qualities of the PCI. Simultaneous Component Analysis (SCA) was used to construct an inventory suitable for assessing pain-coping strategies among various types of chronic pain patients. This factor analytic procedure was applied to data on patients with chronic rheumatoid arthritis, patients with chronic headaches, and a heterogeneous group of pain clinic outpatients. SCA revealed a meaningful factorial solution, which led to the composition of the following cognitive (C) and behavioral (B) scales: Pain Transformation (C), Distraction (C/B), Reducing Demands (C/B), Retreating (B), Worrying (C), and Resting (B). The relatively high internal consistency and temporal stability of these six PCI scales warrant their use for research and clinical purposes. In clinical practice, the scales can be used to assess the individual patient's dominant pain-coping strategies and compare his or her level of pain-coping use to group data from similar types of pain patients. Specific pain-coping scales were not substantially related to the participants' age, gender, or illness duration. These findings are consistent with those in the literature. In its current form, the PCI consists of 33 items and is easy to administer and time efficient.

Support was found for a distinction between "active" and "passive" pain-coping strategies. More specifically, second-order factor analysis grouped the PCI 
scales into two dimensions: the first dimension reflects the patients' cognitive and behavioral efforts to distract themselves from the pain or to function in spite of pain; the second dimension represents behavioral tendencies to restrict functioning and to worry. However, the rather low correlations between the separate PCI scales advocates separate use of the six scales, in addition to the two condensed categories (see also Jensen, Turner, \& Romano, 1992).

The differences in use of strategy found between different types of chronic pain patients indicate that the PCI scales are sufficiently sensitive to measure differences between groups. RA patients and pain clinic outpatients scored higher on two of the three active scales and lower on two of the three passive scales than headache patients. Our finding that headache patients are characterized by using such strategies as Retreating, Worrying, and Resting is consistent with the data from Philips and Jahanshani (1985), who demonstrated higher levels of avoidance in headache patients than in patients with chronic low back pain.

The preferred, most frequently used strategy by all three pain groups was behavioral, that is, Resting for RA patients and pain clinic outpatients, and Retreating for headache patients. Preferred by many, these strategies can have deleterious long-term effects on other aspects of well-being (Kraaimaat \& Huiskes, 1989). For instance, retreating and resting can be indicated for RA patients in periods of increased disease activity. But if these coping strategies are continued when the disease is in remission, it can lead to harmful effects on physical functioning (e.g., decreased muscle strength: Dekker, Boot, Woude, \& Bijlsma, 1992, or increased disability: Jensen et al., 1987). Support for this assumption was found following the 1- and 3-year courses of functional status in patients with recently diagnosed RA. More specifically, pain-coping strategies of Retreating, Worrying, and Resting were found to be predictive of a worse functional status for these patients 1 year later, and Resting was predictive of a worse functional status 3 years later. Whether the adverse long-term effects of these strategies also applies to other types of chronic pain patients remains an open question. In addition, the active strategy of distraction predicted less functional disability after 1 and 3 years. However, because this relation at the 1-year follow-up was not previously found in a larger sample (see Evers, Kraaimaat et al., 1998), further research is needed for the predictive validity of this active pain-coping strategy.

Worrying is conceptualized as the cognitive aspect of pain-related anxiety. It refers to maladaptive thoughts concerning the interpretation and prediction of pain. Although not quite identical, the Worrying scale bears close resemblance to the so-called "catastrophizing" scales in other pain-coping questionnaires (CSQ, PCL). The items in the Worrying scale are less strongly worded than the catastrophizing items in the other scales. There is a debate about the conceptualization of pain-related negative thoughts. Questions have been raised about the validity of catastrophizing-worrying scales. Instead of assessing coping strategies, they may measure psychological symptomatology (Haaga, 1992; Sullivan \& D’Eon, 1990). 
The Worrying scale indeed shows significant correlations with neuroticism, anxiety, and depressive mood. However, the sizes of these coefficients are indicative of an overlap, but not of identical constructs. Jensen et al. (1991) raised the important point that if coping is defined as a purposeful effort to manage stress, negative thoughts in response to pain could more appropriately be conceptualized as appraisal than as coping responses. In our opinion there appears to be a number of benefits to conceiving of Worrying in both ways. Its appraisal function could prevail in exposure to nociceptive stimuli. In the absence of nociceptive stimuli, worrying could be a coping strategy for remaining vigilant of potentially painful stimuli and lead to a continuation of attempts to avoid pain (see also Aldrich, Eccleston, \& Crombez, 2000; Davey, 1993; Eysenck, 1982). The relatively high correlations found in this study between the scales of Worrying, Resting, and Retreating support Philips' (1987) model of chronic pain behavior, in which patients' expectation of pain increment strengthens avoidant behavior and vice versa. Worrying may be conceptualized as entrapping the patient. Attention to pain may increase pain experiences (Arntz \& de Jong, 1991), catastrophic thinking about pain may produce the priming of escape behavior and a general hypervigilance for pain (Eccleston \& Crombez, 1999), avoidance of pain-linked situations has negative reinforcing effects on worrying (Philips, 1987), and avoidance of situations and activities may induce harmful effects on physical functioning (Dekker et al., 1992).

The PCI has a limitation common to all pain-coping questionnaires, involving retrospective assessment (Affleck, Urrows, Tennen, \& Higgins, 1992; Keefe, Salley, \& Lefebvre, 1992). The PCI assesses participants' typical response to pain across situations and does not assess coping with a specific episode of pain. However, it might be possible to create a PCI state form for assessing specific coping episodes by some modifications of the instructions (see also Carver \& Scheier, 1994). Next, the patients' tendency to overreport or underreport coping behaviors may bias scores to some extent. There are several procedures that may be used in the case of small samples to study these distorting influences. For instance, pain and use of pain-coping behavior may be assessed by means of intensive diary methods for patients (e.g., Keefe et al., 1997). In addition, spouses or significant others can be asked to rate patient behavioral coping strategies. An advantage offered by self-report questionnaires such as the PCI is that they gather lots of information in a short period and are cost effective in cross-sectional and prospective studies with large samples. In addition, there is evidence to support that self-report scales for behavioral pain-coping strategies are consistently related to spouse ratings (Jensen et al., 1995). An important next step in research with the PCI is to investigate the relation between the patients' PCI scale scores to those of their dairy ratings of pain-coping strategies and ratings of the patients' pain-coping behavior obtained by significant others.

In conclusion, the PCI reliably assesses six specific, cognitive, and behavioral pain-coping strategies that represent two higher order, passive, and active 
pain-coping dimensions. The PCI scales are sensitive enough to identify differences between pain diagnostic groups in their use of pain-coping strategies. Support for the predictive validity of the PCI scales regarding long-term functional disability was found in patients with recently diagnosed RA.

\section{REFERENCES}

Affleck, G., Urrows, S., Tennen, H., \& Higgins, P. (1992). Daily coping with pain from rheumatoid arthritis: Patterns and correlates. Pain, 51, 221-229.

Aldrich, S., Eccleston, C., \& Crombez, G. (2000). Worrying about chronic pain: Vigilance to threat and misdirected problem solving. Behaviour Research and Therapy, 38, 457-470.

Arnett, F. C., Edworthy, S. M., Bloch, D. A., McShane, D. J., Fries, J. F., Cooper, N. S. et al. (1988). The American Rheumatism Association 1987 revised criteria for the classification of rheumatoid arthritis. Arthritis Rheumatism, 31, 315-324.

Arntz, A., \& de Jong, p. (1991). Anxiety, attention and pain. Behaviour Research and Therapy, 29, 41-50.

Bakal, D. A., Kaganov, J. A., \& Demjen, S. (1983). Headache assessment from a severity perspective. In K. A. Holroyd, B. Schlote, \& H. Zenz (Eds.), Perspectives on research on headache (pp. 45-55). New York: C. F.

Boothby, J. L., Thorn, B. E., Stroud, M. W., \& Jensen, M. P. (1999). Coping with pain. In R. J. Gatchel \& D. C. T. Turk (Eds.), Psychosocial factors in pain (pp. 343-359). New York: Guilford.

Brown, G. K., \& Nicassio, P. M. (1987). Development of a questionnaire for the assessment of active and passive coping strategies in chronic pain patients. Pain, 31, 53-64.

Burckhardt, C. S., Mannerkorpi, K., Hedenberg, L., \& Bjelle, A. (1994). A randomized, controlled trial of education and physical training of women with fibromyalgia. Journal of Rheumatology, 21, 714-720.

Carver, C. S., \& Scheier, M. F. (1994). Situational coping and coping dispositions in a stressful transaction. Journal of Personality and Social Psychology, 66, 184-195.

Davey, G. C. (1993). A comparison of three worry questionnaires. Behaviour Research and Therapy, 31, 51-56.

Dekker, J., Boot, B., Woude, L. H. V. van der, \& Bijlsma, J. W. J. (1992). Pain and disability in osteoarthritis: A review of biobehavioral mechanisms. Journal of Behavioral Medicine, 15, 189-214

Eccleston, C., \& Crombez, G. (1999). Pain demands attention: A cognitive-affective model of the interruptive function of pain. Psychological Bulletin, 125, 356-366.

Everdingen, A. A. van, Jacobs, J. W. G., Siewertsz van Reesema, D. R., \& Bijlsma, J. W. J. (2002). Low-dose prednison therapy for patients with early active rheumatoid arthritis: Clinical efficacy, Disease modifying properties and side effects. A double-blind placebo controlled clinical trial. Annals of Internal Medicine, 136, 1-12.

Evers, A. W. M., Kraaimaat, F. W., Geenen, R., \& Bijlsma, J. W. G. (1998). Psychosocial predictors of functional change in recently diagnosed rheumatoid arthritis patients. Behaviour Research and Therapy, 36, 179-193.

Evers, A. W. M., Kraaimaat, F. W., van Lankveld, W., Jongen, P. J. H., Jacobs, J. W. G., \& Bijlsma, J. W. J. (2001). Beyond unfavorable thinking: The Illness Cognition Questionnaire for chronic diseases. Journal of Consulting and Clinical Psychology, 69, 1026-1036.

Evers, A. W. M., Taal, E., Kraaimaat, F. W., Jacobs, J. W. J., Abdel-Nasser, A., Rasker, J. J., et al. (1998). A comparison of two recently developed health status instruments for patients with arthritis: Dutch-AIMS2 and IRGL. British Journal of Rheumatology, 37, 157-164. 
Eysenck, H. J., \& Eysenck, S. B. (1992). Manual of the Eysenck Personality Scales. London: Hoddor and Houghton.

Eysenck, M. W. (1982). Attention and arousal: Cognition and performance. New York: Springer.

Geden, E., Beck, N., Hauge, G., \& Pohlman, S. (1984). Self-report and Psychophysiological effects of five pain-coping strategies. Nursing Research, 33, 260-265.

Haaga, D. A. F. (1992). Catastrophizing, confounds, and depression: A comment on Sullivan and D'Eon (1990). Journal of Abnormal Psychology, 101, 206-207.

Huiskes, C. J. A. E., Kraaimaat, F. W., \& Bijlsma, J. W. J. (1990). Development of a self report questionnaire to assess the impact of rheumatic disease on health and lifestyle. Journal of Rehabilitation Sciences, 3, 71-74.

Jensen, M. P., Karoly, P., \& Huger, R. (1987). The development and preliminary validation of an instrument to assess patients' attitudes toward pain. Journal of Psychosomatic Research, 31, 393-400. Jensen, M. P., Turner, J. A., \& Romano, J. M. (1991). Self-efficacy and outcome expectancies: relationship to chronic pain coping strategies and adjustment. Pain, 44, 263-269.

Jensen, M. P., Turner, J. A., \& Romano, J. M. (1992). Chronic pain coping measures: Individual vs. composite scores. Pain, 51, 273-280.

Jensen, M. P., Turner, J. A., Romano, J. M., \& Karoly, P. (1991). Coping with chronic pain: a critical review of the literature. Pain, 47, 249-283.

Jensen, M. P., Turner, J. A., Romano, J. M., \& Strom, S. E. (1995). The Chronic Pain Coping Inventory: development and primary validation. Pain, 60, 203-216.

Keefe, F. J., Affleck, G., Lefebvre, J. C., Starr, K., Caldwell, D. S., \& Tennen, H. (1997). Pain coping strategies and coping efficacy in rheumatoid arthritis: A daily process analysis. Pain, 69, 35-42.

Keefe, F. J., Brown, G. K., Wallston, K. A., \& Caldwell, D. S. (1989). Coping with rheumatoid arthritis pain: Catastrophizing as a maladaptive strategy. Pain, 37, 51-56.

Keefe, F. J., Caldwell, D. S., Martinez, S., Nunley, J., Beckham, J., \& Williams, D. A. (1991). Analyzing pain in rheumatoid arthritis patients. Pain coping strategies in patients who have had knee replacement surgery. Pain, 46, 153-160.

Keefe, F. J., Salley, A. N., \& Lefebvre, J. C. (1992). Coping with pain: Conceptual concerns and future directions. Pain, 51, 131-134.

Kiers, H. A. L., \& Berge, J. M. F. ten (1989). Alternating least squares algorithms for simultaneous components analysis with equal component weight matrices in two or more populations. Psychometrika, 54, 467-473.

Kleinke, C. L. (1992). How chronic pain patients cope with pain: Relation to treatment outcome in a multidisciplinairy pain clinic. Cognitive Therapy and Research, 16, 669-685.

Kraaimaat, F. W., Bakker, A. H., \& Evers, A. W. M. (1997). Pijncoping strategieen bij chronische pijn patienten: De ontwikkeling van de PijnCopingInventarisatielijst (PCI) [Pain coping strategies in chronic pain patients: The development of the Pain Coping Inventory (PCI)]. Gedragstherapie, 22, 267-277.

Kraaimaat, F. W., Brons, M. R., Geenen, R., \& Bijlsma, J. W. J. (1995). The effect of cognitive behavior therapy in patients with rheumatoid arthritis. Behaviour Research and Therapy, 33, 487-495.

Kraaimaat, F. W. \& Huiskes, C. J. A. E. (1989). Stress en pijn bij patiënten met rheumatoide arthritis [Stress and pain in patients with rheumatoid arthritis]. Gedragstherapie, 22, 267-277.

Kraaimaat, F. W., \& Schevikhoven, R. E. O. van (1988), Causal attributions and coping with pain in chronic headache sufferers. Journal of Behavioral Medicine, 11, 293-302.

Kraaimaat, F. W., \& Zwart, F. M. (1984). De Hoofdpijn-vragenlijst [The Headache Questionnaire]. Utrecht, The Netherlands: Academic Hospital.

Lawson, K. C., Reesor, K. A., Keefe, F. J., \& Turner, J. A. (1990). Dimensions of pain-related cognitive coping: Cross validation of the factor structure of the Coping Strategy Questionnaire. Pain, 43, 195-204.

Martin, P. R., Milech, D., \& Nathan, P. R. (1993). Towards a functional model of chronic headaches. Headache, 33, 461-470. 
Millsap, R. E., \& Meredith, W. (1988). Component analysis in cross-sectional and Longitudinal Data. Psychometrika, 53, 123-134.

Nunnally, J. C., \& Bernstein, I. H. (1994). Psychometric theory (3rd ed.). New York: McGraw-Hill.

Philips, H. C. (1987). Avoidance behavior and its role in sustaining chronic pain. Behaviour Research and Therapy, 25, 273-279.

Philips, H. C., \& Jahanshahi, M. (1985). The effects of persistent pain: the chronic headache sufferer. Pain, 21, 163-176.

Pilowsky, I., \& Spence, N. D. (1976). Is illness behaviour related to chronicity in patients with intractable pain? Pain, 2, 167-173.

Post, D. (1980). De huisarts en zijn hoofdpijnpatiënten [The general practitioner and his headache patients]. Alphen aan den Rijn, The Netherlands: Stafleu.

Rosenstiel, A. K., \& Keefe, F. J. (1983). The use of coping strategies in chronic low back pain patients: relationship to patient characteristics and current adjustment. Pain, 17, 33-44.

Sanderman, R., \& Ormel, J. (1992). De Utrechtse Coping Lijst (UCL): Validiteit en betrouwbaarheid [The Utrecht Coping List (UCL): Validity and reliability]. Gedrag en Gezondheid, 20, 32-37.

Schevikhoven, R. E. O. van, \& Kraaimaat, F. W. (1987). Omgaan met pijn bij patiënten met chronische hoofdpijn [Coping with pain in chronic headache patients]. Gedragstherapie, 20, 191-202.

Schreurs, P. J. G., Willige, G. van de, Brosschot, J. F., Tellegen, B., \& Graus, G. M. H. (1993). De Utrechtse coping lijst: UCL Handleiding [Manual of the Utrecht Coping List]. Lisse, The Netherlands: Swets, \& Zeitlinger.

Scott, L. E., \& Clum, G. A. (1984). Examining the interaction effects of coping style and brief interventions in the treatment of postsurgical pain. Pain, 20, 279-291.

Smith, C. A., Wallston, K. A., Dwyer, K. A., \& Dowdy, S. W. (1997). Beyond good and bad coping: A multidimensional examination of coping with pain in persons with rheumatoid arthritis. Annals of Behavioral Medicine, 19, 11-21.

Spinhoven, P., Ter Kuile, M. M., Linssen, A. C. G., \& Gazendam, B. (1989). Pain coping strategies in a Dutch population of chronic low back pain patients. Pain, 37, 77-83.

Sullivan, M. J. L., \& D'Eon, J. L. (1990). Relation between catastrophizing and depression in chronic pain Patients. Journal of Abnormal Psychology, 99, 260-263.

Tan, S. Y. (1982). Cognitive and cognitive-behavioral methods for pain control: A selective review. Pain, 12, 201-228.

Tesler, M. D., Wegner, C., Savedra, M., Gibbons, P., \& Ward, J. A. (1981). Coping strategies of children with pain. Issues in Comprehensive Pediatric Nursing, 5, 351-359.

Tuttle, D. H., Shutty, M. S., \& DeGood, D. E. (1991). Empirical dimensions of coping in chronic pain patients: A factorial analysis. Rehabilitation Psychology, 36, 179-188.

Van der Ploeg, H. M., Defares, P. B. \& Spielberger, C. D. (1980). Handleiding bij de Zelf Beoordelings Vragenlijsl, ZBV [Manual of the Dutch version of the State Trait Anxiety Inventory]. Lisse, The Netherlands: Swets \& Zeitlinger.

Verhaak, P. M. F., Kerssen, J. J., Dekker, J., Sorbi, M. J., \& Benzing, J. M. (1998). Prevalence of chronic benign pain disorder among adults: a review of the literature. Pain, 77, 231-239.

Vlaeyen, J. W. S., Geurts, S. M., Kole-Snijders, A. M. J., Schuerman, J. A., Groenman, N. H., \& Eek, H. van (1990). What do chronic pain patients think of their pain? Towards a pain cognition questionnaire. British Journal of Clinical Psychology, 29, 383-394.

Wilde, G. J. S. (1970). Neurotische labiliteit, gemeten volgens de vragenlijst methode [Neuroticism, measured by means of a self report inventory]. Amsterdam, The Netherlands: Van Rossen.

Zwart, F. M. \& Spooren, J. (1982). Ontwikkeling van een zelfbeoordelingsviagenlijst voor depressie [Developemnt of a self-report questionnaire for depression]. Utrecht, The Netherlands: University Medical Center. 